\title{
MECHANISM OF TRANSITION OF FRICTION PAIRS TO “QUASIWEARLESS" MODE OF OPERATION
}

\author{
V.P. Babak, S.F. Filonenko, V.M. Stadnychenko \\ National Aviation University, Kiev, Ukraine. E-mail: stadnichenko_nau@hotmail.com \\ Received 2006-03-20, accepted 2006-12-11
}
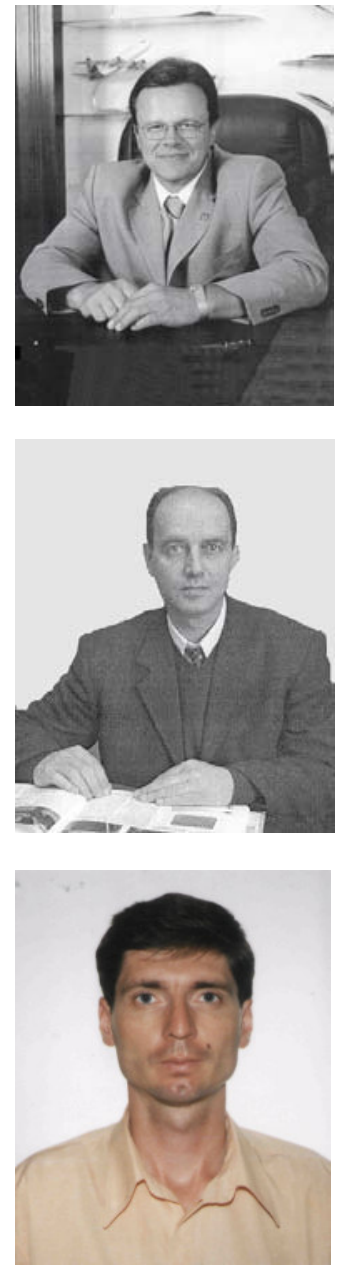

Vitaly BABAK, Prof Dr Habil

A corresponding member of the National Academy of Science of Ukraine, a doctor of engineering science, professor, an honored figure of science and engineering in Ukraine, winner of a Ukrainian state award in the area of science and technique.

Date and place of birth: 1954, Lubny, Ukraine

Education: Kiev Polytechnic Institute, 1977. 1995 - PhD from Kiev Polytechnic Institute.

Affiliation and functions: 1977-1995 - an assistant, an assistant professor, a professor, the head of faculty at Kiev Polytechnic Institute. 1995-1998 - the deputy minister of education of Ukraine. Since 1998 - the president of the National Aviation University, Kiev, Ukraine

Research interests: diagnostics of technological processes, signal processing.

Publications: over 330 scientific papers, including 45 monographs, textbooks, dictionaries, and 36 patents.

Sergey FILONENKO, Prof Dr Habil

Date and place of birth: 1954, Armenia

Education: Kiev Polytechnic Institute, 1977. 2003 PhD from National Aviation University

Affiliation and functions: deputy director of the Institute of Information-Diagnostic Systems at the National Aviation University since 2000.

Research interests: diagnostics of technological processes, automatic diagnostic systems.

Publications: over 130 books and articles

Viacheslav STADNYCHENKO, CtS

Date and place of birth: 1971, Moldova

Education: Kharkiv Military Aviation Engineering School, 1993 (diploma in mechanic engineering). 1997 - PhD from NSRI "HYDROPRIVOD”.

Affiliation and functions: assistant professor at National Aviation University since 2003.

Research interests: diagnostics of technological processes, automatic diagnostic systems, friction and wear.

Publications: over 30 articles and monographers.

Abstract. This article describes the results of research of the acoustic emission of friction pairs in the process of their operation. The dependences of the parameters of acoustic emission that correspond to the alteration of the energy dissipation mechanism of the superficial layers of friction pairs at the transition to "quasiwearless" mode of their operation are obtained.

Keywords: acoustic emission, strength, friction pair, and "quasiwearless" mode of operation, fracture, tryboretrofitting mixes.

\section{Introduction}

The use of tryboretrofitting mixes (TRM) is one of the ways to prolong the service life of modern technological units. The application TRM is directed to the recovery of trybotechnical friction surfaces without carry- ing out labor-intensive operations that are connected with dismantling units after their repair $[6,1]$.

Present requirements for the of application TRM do not take into account the specific kinetics of physical and chemical processes that originate on the friction surface due to the application of TRM. Above all things, this relates to the determination of the conditions for the origin 
and operation of metallic and ceramic layers (MCL). Both on stationary and unstationary exploitation modes of aviation and ground technical equipment.

One of the methods that allow one to obtain information about the kinetics of processes that take place in the surface layers of materials at the moment of their dynamic contact interaction is the acoustic emission (AE) method $[4,2,5]$. This method has a high sensitivity to the change in element wearing mechanisms that are due to physical and mechanical processes taking place in the materials on the interface of contact surfaces.

This fact allows one to apply AE information for developing the methods of evaluating the state of the friction pairs, the wear stages of the materials. Thus the method is promising from the point of view of the studies of the mechanism of the transaction of the friction pair to a "quasiwearless" mode of operation.

This paper will prove that at adding TRM the mechanism of energy dissipation that is accumulated in the superficial layer of material due to the turning-isomer motion is substituted for the mechanism of energy dissipation because of macro shifting of the whole superficial layer takes place. It causes an alteration of the contact interaction conditions and the conditions of friction pair transition to the "quasiwearless" mode operation. The basic dependences of AE, which can be used for the development of estimation methods for the condition of friction surfaces at the process of exploitation, will also be defined.

\section{Investigation methods}

Two pairs of samples made of ШX-15 and $12 \mathrm{X} 2 \mathrm{H} 4 \mathrm{~A}$ steel were prepared. These materials for the friction pair under investigation and the lubricant environment were chosen because of their wide use in aircraft GTE transmissions. Testing of samples was performed with the help of the universal friction machine CMT-1 on the "disk to disk" scheme. According to this arrangement, one disk was stationary while the other was rotating on the spindle of the friction machine. During tests the mode of rolling friction with $20 \%$ slippage was realized. Samples dimensions were: diameter $D_{\mathrm{sam}}=25 \mathrm{~mm}$, thickness $h=15 \mathrm{~mm}$.

The temperature of the lubricant environment was $373^{\circ} \mathrm{C}$ and remained constant due to the thermoregulation system. The given temperature corresponds to the working temperature of the lubricant environment of helicopter reduction gears and bearing parts of helicopter gas turbine engines. The speed of rotation of the friction machine transmission shaft was chosen to be as close as possible to the condition of operation of modeling units and was equal to $500 \mathrm{rpm}$.

Both the friction pair without MCL and the friction pair with MCL were tested for deterioration under loading. MCL was created after putting the lubricant TRM "KOMBAT" between contact surfaces of samples according to the technology described in work [1].

The tests were performed in two stages. First, friction pairs were tested under loading. Load applied to the friction pairs was converted into the applied stress with the use of the dimensions of tested samples. Initially applied stress was $\sigma_{\max }=1000 \mathrm{MPa}$. Methods of stress calculation are given in [*]. After the output of friction pair in a mode of the steady wear and a long operation in this mode (not less than 30 hours), instant alteration in the pressure up to $\sigma_{\max }=600 \mathrm{MPa}$ took place. The range of a change in the contact stresses on the samples was selected from the conditions for their correspondence to operational loadings that arise on contact spots of reduction gear cogs and rolling bodies of helicopter engines.

In the second stage, after no less than 5 hours of work under the loading $\sigma_{\max }=600 \mathrm{MPa}$, instant loading of friction pairs up to a level of $\sigma_{\max }=1000 \mathrm{MPa}$ with their further work in the given mode took place.

The moment of friction and sample weights that were determined according to the methods described by Х. Чихос, were considered the main parameters characterizing wear resistance of samples [11].

During the friction process, the recording and processing of AE signals were performed. The acoustic emission unit included an AE 109M unit that had the output of information into two recording devices: an H306 and a PC. Primary transformation of information was made by means of a transducer made of ЦТС-19 type piesoceramics.

The transducer was placed on a waveguide that had a rigid contract with the stationary part of the friction pair. The transducer output signal was too weak to be processed by electronic devices. The signal was amplified and selected from noise with the help of a preliminary amplifier. The frequency range of recorded AE signals was between $500 \mathrm{kcps} 1 \mathrm{mcps}$. Average amplitude, average power, and average accumulated power were among the AE signal parameters that were recorded. Time of averaging is equal to $0.2 \mathrm{~s}$.

In the process of research, an analysis of the structural and chemical composition of MCL was carried out. This was performed with the help of a CamScan-4DV raster electronic microscope-analyzer of at magnification $\mathrm{x} 300$.

\section{Results of research}

The results of the research of friction pairs without MCL have shown the following. In the process of a contact interaction with applied loading of $1000 \mathrm{MPa}$, the gradual transition of the friction unit from the run-in regime shifted to the steady wear regime. This regime is characterized by the stabilization of the friction moment value at the level $\mathrm{M} \approx 5.6 \mathrm{n} / \mathrm{m}$ (stage 1, Fig $1 a$ ). After a decrease in loading to $600 \mathrm{MPa}$, an instantaneous drop in the friction moment to the value of $\mathrm{M} \approx 4.3 \mathrm{n} / \mathrm{m}$ was observed $(A$, Fig $1 a)$.

Afterwards, gradual increase in the friction moment was observed $(B$, Fig $1 a)$. This increase takes place for approximately 1 hour of the contact interaction of the friction surfaces of samples under investigation.

*) Справочник по триботехнике. Теоретические основы. Под общ. ред. М. Хебды; А.В Чичинадзе. М.: Машиностроение, 1989, т. 1, $400 \mathrm{c}$. 
After this, the stabilization of friction moment occurs at a new level, the value of which was: $\mathrm{M}_{\mathrm{f}} \approx 4.5 \mathrm{H} / \mathrm{M}$ (stage 2, Fig $1 a$ ). It is evident from the results obtained that the difference between the instantaneous values of friction moment $\mathrm{M}$ at the moment of time after the loading alteration and its stabilization on the new level comprises: $\Delta \mathrm{M}_{\mathrm{f}} \approx 0.2 \mathrm{~N} / \mathrm{m}$. After 5-hour work of the friction pair without MCL in the new stabilization regime, an instantaneous increase in the applied loading up to the initial value $\left(m_{a x i}=1000 \mathrm{MPa}\right)$ was conducted. On the diagram of Mf alteration, this transition is characterized by a sharp spasmodic increase in the friction moment $(C$, Fig 1 a) to the level of $\mathrm{M}_{\mathrm{f}} \approx 5.9 \mathrm{~N} / \mathrm{m}$, which exceeds the level of the initial stabilization with the same value of loading.

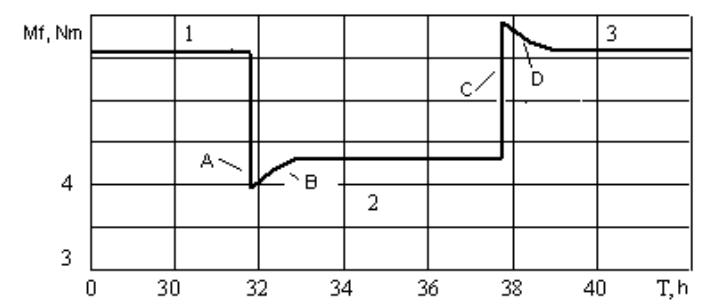

$a$

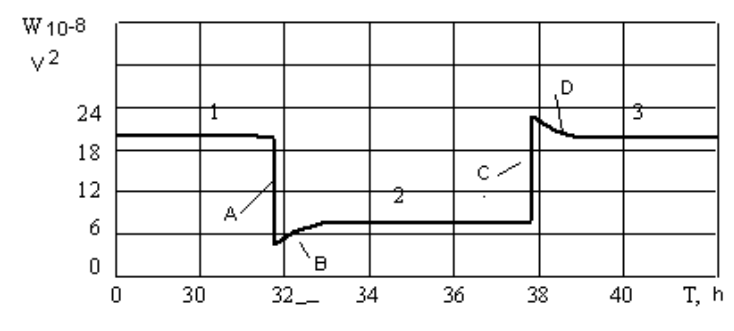

b

Fig 1. Associations of $M_{f}$ (a) and average power signals $W$ from time (friction pairs without MCL). Value of applied loading: "1.3," $-\sigma_{\max }=1000 \mathrm{MPa} ; 2-\sigma_{\max }=600 \mathrm{MPa}$

Later a smooth decrease in $\mathrm{M}_{\mathrm{f}}$ is observed $(D$, Fig 1 a) with its gradual stabilization at the new level (stage 3 , Fig 2 a). This stage of stabilization is characterized by a friction moment value that insignificantly exceeds the stabilization level. As the analysis of observations showed, the average deviation in the friction moment $\Delta \mathrm{M}$ during stage 3 for all the tests performed was approximately $0.5 \%-0.7 \%$. A smooth alteration in friction moment $\mathbf{M}_{\mathrm{f}}$ occurred with the activation of stabilization, both in the case of the decrease and in the case of the increase in the applied loading $(B, D$, Fig $1 a)$. This is obviously connected with the appearance and the leadtime of the second run-in process, which is the consequence of the energy dissipation in the surface layer due to the rotary-isomeric motion of its subunits. This coincides with the results of the research in $[10,3,7]$.

It also arises from the data obtained that the structural adaptability at the alteration of loading does not occur instantly but takes place over a sufficiently long interval. It should be noted that this time interval is approximately identical both in the case of increasing and decreasing applied loading. This makes it possible to assume that the mechanisms of the structural adaptability of the surface layers of the materials of friction pairs, under the alteration of the external factors, are similar to each other.

The results of processing AE signals have showed that the character of the alteration of the average power of $\mathrm{AE}$ wholly repeats the character of the alteration in the friction moment. In this case, it is possible to mark out three characteristic stages on the acoustic diagram, and also the stages that correspond to the stages of the appearance and passing of the second run-in of friction pairs $(1,2,3, B, D$, Fig $1 b)$. The time of the smooth alteration of the averaged power of the registered signals at the stage of run-in is however more than the time of the alteration of the friction moment $(B, D$, Fig $1 b)$.

Processing the results obtained showed that the duration of the second run-in, which is fixed, using the friction moment, with the decrease in the loading applied is 3 $\%$ less than with the increasing in loading applied. However, in contrast to the stages of the stabilization stages of friction moment which are characterized by their numerical values, the average power of AE signals at the given stages does remain in effect constant and has a value of $\mathrm{W}=22 \cdot 10^{-6} \mathrm{~B}^{2}$ (stage 1 , 3, Fig $1 \mathrm{a}$ ). That indicates that with the return of maximum loading, applied to the friction pairs, there wear occurs by the same mechanism. The results of the research of friction pairs with MCL at the same operation modes showed that the diagrams of alteration of the friction moment, the averaged power $\mathrm{AE}$ signals are differed from diagrams, the obtained with the testing friction pairs without MCL. In this case, the sections of instantaneous alteration of the loading and transitions to the stabilized "out-wear" stages with the absence of the sections of the second run in are fixed in the diagram (Fig $2 a$ ).

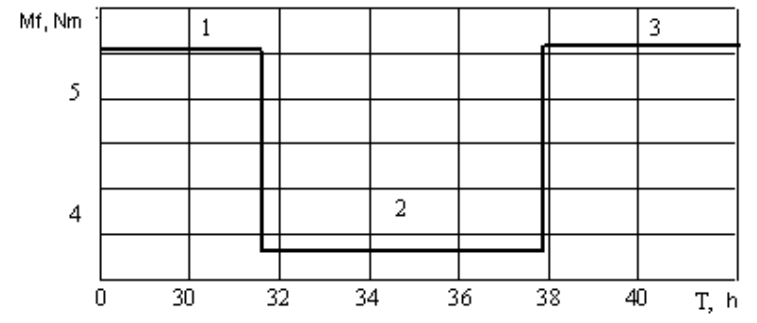

$a$

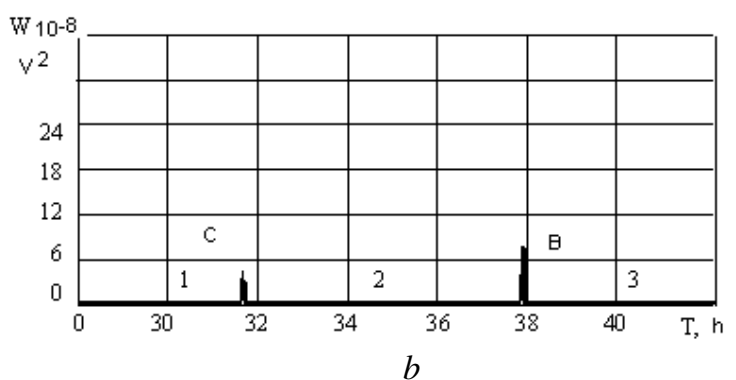

Fig 2. Associations of $\mathrm{M}_{\mathrm{f}}$ (a) and average power signals $\mathrm{W}$ from time (friction pairs with MCL). Value of loading applied: $1.3-\sigma_{\max }=1000 \mathrm{MPa} ; 2-\sigma_{\max }=600 \mathrm{MPa}$

As described above, the return of loading to the initial value $\left(\sigma_{\max }=1000 \mathrm{Mpa}\right)$ is accompanied by an increase of $\mathrm{M}_{\mathrm{f}}$ at the third stage of stabilization 3 (Fig $2 a$ ). This increase in $\Delta \mathrm{M}$ for all tests performed composes ap- 
proximately $0.3-0.6 \%$, relative to the first stage of stabilization 1 (Fig $2 a$ ). The absence of sections of smooth alteration of $\mathrm{M}_{\mathrm{f}}$ with the alteration in the applied loading, as a rule, can be explained by the close to "instantaneous" structural adaptability of MCL to the new operating mode, without revealing the physical essence of the phenomenon.

At the same time, on the averaged power change diagrams of $\mathrm{AE}$ signals, short-term splash of acoustic emission approximately 6-8s are observed (C, B, Fig 2 b). They are fixed at the moments of the time of a change in the applied stress in the stabilization phases $M_{\mathrm{f}}(2,3$, Fig 2 a). Subsequently acoustic emission is absent.

It should be noted that the concept of an "instantaneous" alteration in the applied stress is sufficiently relative. Taking into account its stabilization, the setting of the new loading value can occur in $2-3 \mathrm{~s}$. At the same time, AE is fixed during considerably wide time interval. This indicates that with the instantaneous alteration of the applied loading of the friction pairs with MCL, the second run-in also takes place also, but in this case the energy dissipation of friction surfaces passes due to the macro shifting processes of the entire surface layer.

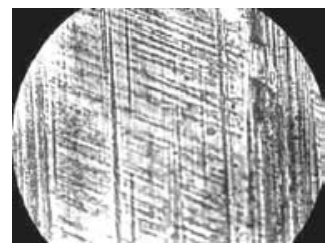

a

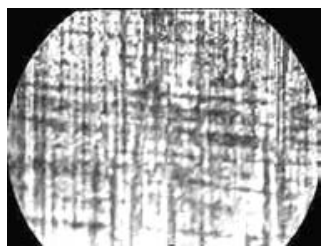

C

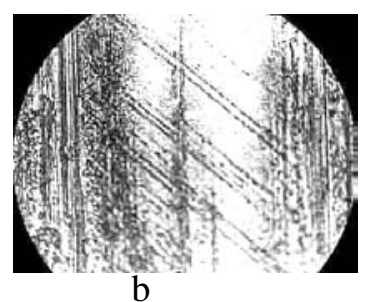

Fig 3. Fractographies of MCL surface at "instantaneous" alteration of applied loading $(\times 300)$ : a; c $-\sigma=1000 \mathrm{MPa}$, stages 1,$3 ;$ в $-\sigma=600 \mathrm{MPa}$, stage 2

The results of fractography analysis of the surfaces of the friction pairs obtained at different stages of loading correspond to this fact (Fig 3). As can be seen from figure 3 the macro shifting deformations are observed at all stages of friction stages. In the case with the transition from stage 1 to stage 2 (Fig $3 a, b$ ), a decrease in macro shifting deformations (typical shift strips) is observed. It is obvious that this is caused by the decrease in the thickness of the surface layer due to the decrease in the value of loading applied. However, with the subsequent increase in the loading applied, an increase in the macro shifting deformation, which covers entire surface of the model, is observed.

\section{Results discussion}

From position of the synergistic approach, the changing of dissipation's mechanism of energy accumu- lated in the superficial layer of material because of turning-isomer motion to the dissipation' mechanism due to the macro shifting moving of all layer precedes to the achievement by the system and its components the bifurcation's points (instability).

The internal alteration of structure submits to LeShatelier-Braun's principle or the principle of the least compulsion determining the stability of a thermodynamic system when external conditions of friction change $[8,9]$.

The irreversible character expressed in production of entropy is a common feature of transformations in trybosystems. A balance of energy at friction from the thermodynamics analysis position is possible to represent in a form reflecting the first and second basis of thermodynamic:

$$
\rho T d S=\rho d U-\sigma_{i k} \cdot \bar{d} \varepsilon_{i k}-Y_{j} d Z_{i} A_{\kappa} a_{k},
$$

where $S$ and $U$ are specific value of entropy and internal energy of material; $\rho$ and $\mathrm{T}$ are density and temperature; $\sigma_{i k}-$ tensor tension; $\varepsilon_{i k}-$ tensor of deformations (elastic and plastic); $\mathrm{y}_{\mathrm{j}}$ and $\mathrm{Z}_{\mathrm{i}}$ are local values of chemical potential and concentration component; $A_{k}$ and $a_{k}-$ common forces and co-ordinates.

$\rho \frac{\partial^{\mathrm{i}} \mathrm{s}}{\partial \mathrm{t}}=\left\{\rho \frac{\partial^{\mathrm{i}} \mathrm{s}}{\partial \mathrm{t}}\right\}_{\mathrm{b}}-\frac{\mathrm{q}}{\mathrm{T}^{2}} \operatorname{grad}\left(\varphi^{(\mathrm{e})}-\varphi\right)-\left\{\rho \frac{\partial^{\mathrm{I}} \mathrm{s}}{\partial \mathrm{t}}\right\}_{\text {Д }}$,

where $\left\{\rho \frac{\partial^{i} \mathrm{~s}}{\partial \mathrm{t}}\right\}_{\mathrm{b}}$ - dissipation of mechanical energy due to viscosity of material;

$\frac{\mathrm{q}}{\mathrm{T}^{2}} \operatorname{grad}\left(\varphi^{(\mathrm{e})}-\varphi\right)-$ heat stream, density of which is characterized by heat conduction tensor $\lambda_{\mathrm{ik}}=\lambda_{\mathrm{ki}}$.

Taking into account heat conduction $\mathrm{q}_{\mathrm{i}}=-\lambda_{\mathrm{ik}} \frac{\partial \mathrm{T}}{\partial_{\mathrm{xk}}}$, the substance stream is determined with the help of chemical potentials $\left(\varphi_{\mathrm{i}}-\varphi\right)$, which give the meaning of excess local chemical potential to the given component.

Analyzing the given definition, we should admit that rheology which is determined by chemical interaction of MCL with environment influences the MCL's weariless.

The stream density has such a view:

$$
\mathrm{j}_{\mathrm{i}}=\gamma_{\mathrm{ik}}^{(\mathrm{j})} \frac{\partial\left(\varphi_{1}-\varphi\right)}{\partial \mathrm{x}}
$$

where $\gamma_{\mathrm{ik}}-$ kinetic coefficient of the mass transfer, $\gamma_{\mathrm{ik}}$ $\sim \mathrm{D}_{\mathrm{ik}}$, and $\mathrm{D}_{\mathrm{ik}}-$ self-diffusion tensor.

Heat stream density

$$
\mathrm{q}_{\mathrm{i}}=-\lambda_{\mathrm{ik}} \frac{\partial \mathrm{T}}{\partial \mathrm{x}_{\mathrm{k}}}
$$

where $\lambda_{\mathrm{ik}}=\lambda_{\mathrm{ki}}-$ heat conduction tensor.

The analysis of wear process on the basis of the approach taken allows one to make the conclusion that the 
transfer of matter in the thermodynamic system of friction units is mediated by the density of the heat buildup stream dissipation, and chemical potential of system elements.

At quite a high level of micro hardness $\left(\mathrm{H} \mu=910 \mathrm{~kg} \backslash \mathrm{mm}^{2}\right)$, commensurable with the micro hardness of the basic material $\left(\mathrm{H} \mu=950 \mathrm{~kg} \backslash \mathrm{mm}^{2}\right)$, and because of it the accordingly high limit of fluidity $\sigma_{\mathrm{s}}=303$ $\mathrm{MPa}$ and shift strength $\tau_{\mathrm{s}}=151 \mathrm{MPa}$, a MC layer possesses viscous plastic properties.

The carrying out of MC layer in the field of operating tensions could be accounted with the help of Prandtel's theological model, which characterizes the conduct of viscous plastic bodies [5]. For this model, characteristically, elastic and plastic deformations do not arise instantly after loading, but develop in time.

A MCL is in the conditions of the difficult tense state (DTS), because tangent and twisting tensions and also normal tensions of tension-compression and longitudinal bend, operate simultaneously on it. The real picture of the tensely deformed state of MC-layer could be estimated using the equivalent tensions, which are defined according to the IV power strength hypothesis of S. Timoshenko:

$$
\sigma_{\text {экв.IV }}=\sqrt{\sigma_{\Sigma}^{2}+3 \tau_{\Sigma}^{2}}
$$

Where $\sigma_{\Sigma}$ are total normal tensions in the weak section and $\tau_{\Sigma}$ are total tangent tensions in the weak section. The section will be the weak section, where maximal contact pressure of $\mathrm{q}_{\max }$ operates.

For verification of rightness of $\sigma_{\Sigma}$, it is possible to use the dependence for determination of middle normal tension in the contact area of an absolutely hard ball with the flat surface of the resiliently deformed material (the Winkler's volume model) [15]:

$$
\sigma_{n}=\frac{0.42 E_{n p .}}{\left(1-v_{n p}^{2}\right)} \sqrt{\frac{h}{R}},
$$

where $R$ - radius of sphere-indicator, $v_{\text {пр }}$ - Puasson's reduced coefficient of material with MC-layer, $E_{n p}$. - reduced elasticity module of material with MC-layer, $h$ - width of the deformation zone MCL $[2,5]$.

A MC-layer is in the conditions of plasticity and after flow. They appear at the conditions arise of the unstationary external loading, this why it is possible to name them dynamic after flow.

A calculation for dynamic after flow is taken to determination of durability of component with MCL at known or set temperature, equivalent tensions and border deformation. Using the border relative deformation $(\varepsilon)$, and Velar's curves for this temperature, it is possible to set duration $\mathrm{N}$, which corresponds to the characteristic values of $\sigma_{e q l}$ or $\sigma_{-1}$. A reverse task - the determination of tension boundary conditions using duration $\mathrm{N}$ and boundary relative deformation $(\varepsilon)-$ is fixed in the same way.

At elastic fluids in the spots of contact with MCL, cycle life is defined according to Winkler's model:

$$
n=\left(\frac{\sigma_{B}}{\sigma_{p}}\right)^{m}
$$

where $\sigma_{B}$ - proof strength, MPa; $\sigma_{p}$ - tensions stretch - squeeze, caused by friction forces, MPa; $m$ is index of degree in Velar's classic equation and depends on physicmechanical properties of material - for the high-alloyed heat-resistant constructions steels $\mathrm{m} \approx 4[5, *]$.

In the case of plastic unsaturated contact, frequent plastic deformation causes the wear from low-cycle fatigue. In this case, the number of cycles to destruction is equal to:

$$
n=\left(\frac{2 \varepsilon_{B}}{\varepsilon_{t}}\right)^{m},
$$

where $\varepsilon_{6}-$ deformation, corresponding with proof strength $\sigma_{B} ; \varepsilon_{t}-$ deformation, originating from friction force input.

At the resilient unsaturated contact $\tau_{n}=\tau_{o}+\beta \cdot q_{\max }$, where $\tau_{o}$ and $\beta$ are friction characteristics that depend on the working conditions of friction pairs [11]. We will get the basic indexes of wear, namely the coefficient of friction $\mu$, intensity of wear Ih, and specific pressure in the contact spot $\mathrm{q}_{\max }$ depending on the parameters of DTS and physic-mechanical properties of the material:

$$
\begin{gathered}
\mu=1.4\left[\frac{\tau_{0} \alpha\left(1-v_{n p .}^{2}\right)}{E_{n p .}}\right]+\beta ; \\
I_{h}=\frac{1.5}{n \alpha}\left(\frac{h}{R}\right)^{\frac{1}{2}} ; \\
q_{\max }=1.66\left[\frac{\tau_{0} E_{n p .}}{\left(1-v_{n p .}^{2}\right) \alpha}\right]^{\frac{1}{2}} .
\end{gathered}
$$

\section{Conclusion}

The basic regularities of alteration in the average power of AE signals at different workloads of friction pairs are set up. It is shown that for the friction pair without TRM the character of change in AE diagrams corresponds to the character of diagrams of change of friction moment.

Similarity of temporal areas of the second run-in, which are fixed after the AE signals, and the stability of $\mathrm{AE}$ emission value at the same value of the operation loading testifies to the likeness of mechanisms of structural adjustment of friction pair materials at the procession of their exploitation.

The presence of AE splashes registered during small time intervals at the change of loading conditions of fric-

*) Справочник по триботехнике. Теоретические основы. Под общ. ред. М. Хебды; А.В Чичинадзе. М.: Машиностроение, 1989, т. $1,400 \mathrm{c}$. 
tion pair with MCL, in the absence of friction moment alteration, allows one to draw a conclusion about the existence of the second run-in. However, it takes place with considerable velocity in the short time interval due to the macro shifting processes of the entire surface layer. It is confirmed by the results of fractography analysis.

A substance transition in the thermodynamic system of the friction unit in the process of "quasiwearless" mode of exploitation is mediated by heart-flux density, energy dissipation, and chemical potential of elements of the system. The use of approach allows one to explain MCL performance that was obtained due to TRM application and allows one to define technological, scientifically grounded recommendations for their usage.

\section{References}

1. BABAK, V.P.; STADNICHENKO, V.V. Application of revitalisants for extension of resource and restoring of worn-out friction units of aviation axial-piston hydro machines. Aviation, vol. 8, no 1 , p. 8-12.

2. BENADBALLACH, HS. Terminological properties and acoustic emissions of some thermoplastics sliding against SAE52100. Journal of Tribology. Jan 2006, vol. 128, issue 1, p. 96-102.

3. FISHER, RA. Statistical methods for research works. Edinburgh: Oliver and Rudyard, 1958, $261 \mathrm{p}$.
4. KOHN, DH et al. Methods of Detecting and Predicting Micro fracture in Titanium. In Medical Applications of Titanium and Its Alloys: The Material and Biological Issues, ASTM STP 1272. Edited by. SA. Brown and JE. Lemons. Philadelphia, PA: ASTM, 1996, p. 117-135.

5. БАБАК, В.П.; БАЙСА, Д.Ф.; РІЗАК, В.М. et al. Конструкційні та функціональні матеріали. Київ: Техніка, 2004. ч.2, 363 с.

6. БУЛАТОВ, В.П.; КИРЕЕНКО, О.Ф. Структурное исследование механизмов безызносного трения конструкционных материалов на основе синергетических представлений. Проблемь машиностроения и надежности машин. 1991, №2, с. 56-61.

7. ГАРКУНОВ, Д.Н. Триботехника. 2-е изд., перераб. и доп. М.: Машиностроение, 1989, $328 \mathrm{c}$.

8. КОСТЕЦКИЙ, Б.И. Трение, смазка и износ в машинах. Киев: Техника, 1970, 263 с.

9. НИКОЛИС, Д. Динамика неравновесных систем. М. Мир, 1989. 486 с.

10. РОЗЕНБЕРГ, О.А.; ДЕЛЕВИ С.Е.; ШЕЙКИН В.Н. и др. О структуре поверхностного слоя стали 100Cr6, обработанной лезвийным инструментом из композита 10. Сверхтвердые материаль, 1999, №5. с. 57-62.

11. ЧИХОС, Х. Системный анализ в трибонике. М.: Мир, 1982, 352 с. 